\title{
Influence of the 3D Printing Process Settings on Tensile Strength of PLA and HT-PLA
}

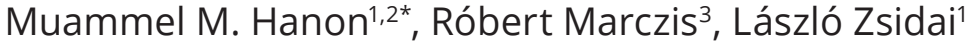 \\ ${ }^{1}$ Mechanical Engineering Doctoral School, Szent István University, H-2100 Gödöllő, Páter Károly utca 1, Hungary \\ 2 Baquba Technical Institute, Middle Technical University (MTU), Baghdad, Iraq \\ 3 Institute for Mechanical Engineering Technology, Faculty of Mechanical Engineering, Szent István University, H-2100 Gödöllö, \\ Páter Károly utca 1, Hungary \\ * Corresponding author, e-mail: Sharba.Muammel.M.Hanon@phd.uni-szie.hu
}

Received: 04 January 2020, Accepted: 13 October 2020, Published online: 27 November 2020

\begin{abstract}
Fused Deposition Modelling (FDM) is presently the most common utilized 3D printing technology. Since this printing technology makes the bodies anisotropic, therefore, investigate the process with different settings is worthwhile. Tensile test specimens of two plastics have been carried out to examine the mechanical properties. Polylactic acid (PLA) and High Temperature PLA (HT-PLA) are the used materials for this purpose. A total of seventy-two test pieces of the two used polymers were printed and evaluated. Three parameters were examined in twelve different settings when printing the tensile test specimens. The considered settings are; six raster directions, three build orientations and two filling factors. The differences in stress-strain curves, tensile strength values and elongation at break were compared among the tested samples. The broken specimens after the tensile test are illustrated, which gave insight into how the test pieces printed with different parameters were fractured. The optimum printing setting is represented at crossed $45 /-45^{\circ}$ raster direction, $X$ orientation and $100 \%$ fill factor, where the highest tensile strength of 59.7 MPa at HT-PLA and the largest elongation of about $3.5 \%$ at PLA were measured.
\end{abstract}

Keywords

3D printing settings, HT-PLA polymer, tensile test specimens

\section{Introduction}

The $3 \mathrm{D}$ printing is an additive manufacturing process starts with a 3D model of a body that is produced using CAD software or scans an existing object. This model must be converted to STL (Stereolithography) file format [1]. A specialized software slices the model horizontally to produce body cross-sections for each height that is transmitted from the computer to the $3 \mathrm{D}$ printer. These slices represent the two-dimensional contour of the model, which if put together, will release the original three-dimensional body. In addition, it is possible to choose the thickness of the layers, which essentially means the printing resolution [2].

There are several 3D printing technologies, all of which are based on a different principle of the three-dimensional body. Fused Deposition Modelling (FDM) is the widely used technology. Its popularity is due primarily to; it offers low cost and a wide range of materials, durable and powerful items, and print speed [3]. During the process, the wire or filament passes through the heated print head and melts. The wire then enters the nozzle, and the molten polymer is discharged from it. By depositing the material in a molten state, it can adhere to previously deposited layers [4]. The worktable on which the piece is located moves downward in the $\mathrm{Z}$ direction. Thus, after a certain period, a real three-dimensional body is created, which is the same as the designed model. Some FDM printers also have a second print head extruding the support material. Due to material separation, the three-dimensional body has anisotropic properties [5].

Polylactic acid (PLA) [6] and acrylonitrile butadiene styrene (ABS) [7] currently are the most common materials used to fabricate objects by $3 \mathrm{D}$ printing. These polymers have temperatures to some extent low make them convenient to be melted during the extrusion of the FDM process, while adequate to keep the shape of the prints at moderate use temperatures. 
In literature, there are many studies performed to improve the mechanical properties of the $3 \mathrm{D}$ printed objects, particularly the tensile strength. This achieved by modulating the process parameters of $3 \mathrm{D}$ printing (such as: fill factor, layer thickness, print speed, closed spaces, etc.) which can fundamentally change previously developed design methods. Letcher and Waytashek [8] employed PLA filament to print specimens at various raster orientation angles which are $0^{\circ}, 45^{\circ}$ and $90^{\circ}$. The results indicated a noticeable impact on the tensile, flexural, and fatigue tests for the printed parts due to the different printing orientations. Tymrak et al. [9] studied the characteristics of mechanical properties of 3D printed ABS and PLA. They utilized tensile test samples made using open-source Rep-Rap 3D printers. Pattern orientation and layer thickness are the main slicing variables which were taken in the $3 \mathrm{D}$ printing process. They found that tensile strength and the elastic modulus of the parts produced by the above 3D printers are comparable to components printed by common 3D printing technologies. Extra studies about the influence of structure patterns [10], fill raster orientation [11, 12], and different geometries [13] on the mechanical properties of $3 \mathrm{D}$ printed tensile test specimens are exist in the cited researches.

This study aims to examine the process parameters settings of $3 \mathrm{D}$ printing in relation to the mechanical properties, to enrich the existing information on mechanical aspects. FDM 3D printing technology has been chosen for producing PLA and High Temperature PLA (HT-PLA) tensile test specimens. In order to survey the impact of varying raster direction angles, spatial orientations, and filling percentage of the $3 \mathrm{D}$ printing process on the tensile strength. The novelty of the current work comes from that the 3D printing process settings of HT-PLA never been studied in the literature, as well as the variety of the examined parameters (twelve different setting) for each material.

\section{Materials and methods}

\subsection{Anisotropy of 3D printed bodies}

Once the STL file of the model completed, it is imported to the previously mentioned slicing program, where a variety of settings can be chosen. These settings are expected to affect the properties of the finished object. Of these, three are examined in this paper as presented in the following.

\subsubsection{Filling raster directions}

Raster direction means, the orientation of the extruder head when filling the printing material within the contour of the printed part. The angle of the raster directions of the test piece with the longitudinal axis can be adjusted to any value. Some examples can be seen in Fig. 1.

In addition, successive layers may have different orientations. So, there is a possibility of variation, e.g. if the raster direction angle of the first layer is $45^{\circ}$ the second could be built at $-45^{\circ}$. Hence, the raster of the consecutive layers is cross, and the angle between every two layers is $90^{\circ}$.

\subsubsection{Test orientation}

Mechanical properties can also be influenced by the spatial location and orientation of the body. The three main orientations $(X, Y$, and $Z$ ) are shown in Fig. 2. In the $Y$ orientation printing, the support material is required, since the essential section of the sample is the part that requires the support.

\subsubsection{Filling factor and pattern}

Another option is to select the fill factor. This reduces the print time and the amount of raw material used. Filling percentage may range from 0 to $100 \%$. An example of bodies printed with different fill factors can be found in Fig. 3.

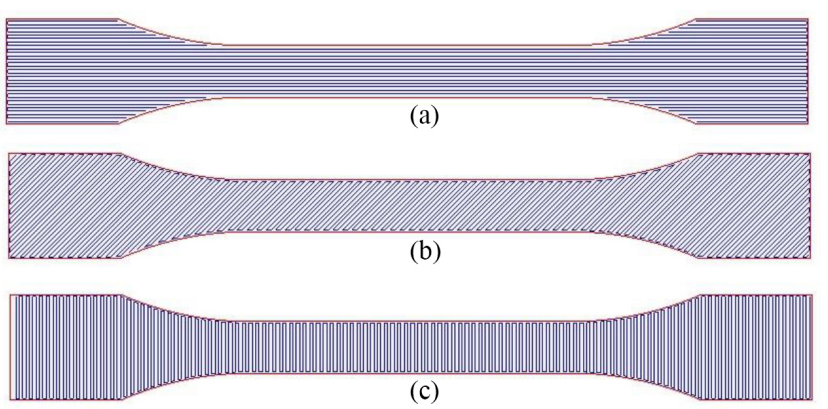

Fig. 1 Raster direction angles: (a) $0^{\circ}$, (b) $45^{\circ}$, and (c) $90^{\circ}$

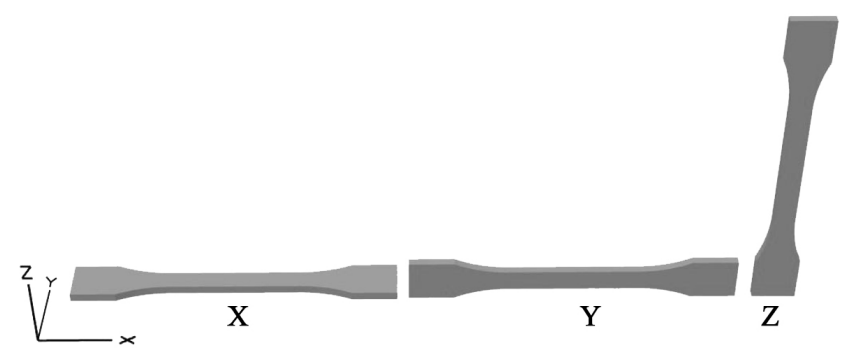

Fig. 2 Spatial orientations of the 3D printed specimens 


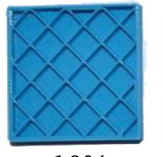

$10 \%$

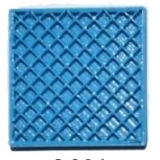

$20 \%$

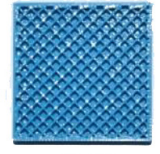

$30 \%$

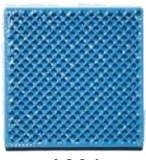

$40 \%$

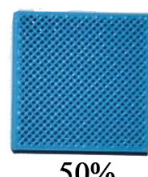

$50 \%$

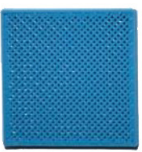

$60 \%$

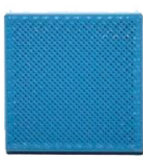

$70 \%$

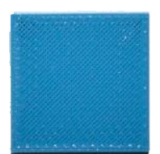

$80 \%$

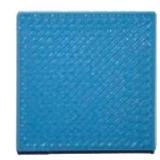

$90 \%$
Fig. 3 Various filling percentage of 3D printed samples

The other parameter is the fill pattern. Fig. 4 shows patterns that can be set in the slicing program. For complete filling, the body is built up according to the previously mentioned fill factor. The higher the percentage, the denser the fill pattern.

\subsection{Preparation for tensile measurement}

The tensile test specimens were modelled according to ISO 527-2: 2012 standard [14] type 1B specimens, which its dimensions are listed in Table 1.

For the tensile strength measurement, Zwick/Roell Z100 machine was used. The experiments have been carried out at a speed of $10 \mathrm{~mm} / \mathrm{min}$ and $20{ }^{\circ} \mathrm{C}$. The specimens were in a room with humidity of $45-50 \%$ for 24 hours prior

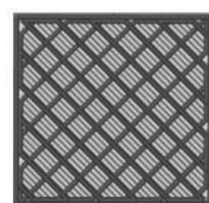

(a)

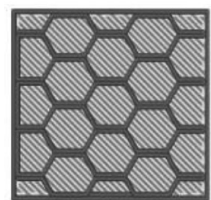

(d)

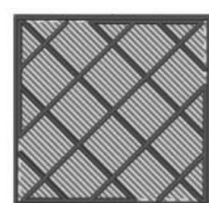

(b)

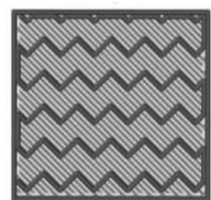

(e)

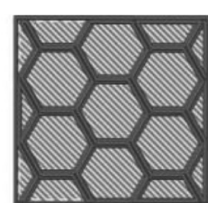

(c)

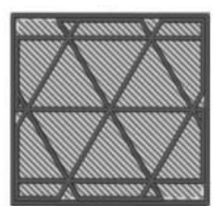

(f)
Fig. 4 Fill patterns available in the slicing program: (a) straight, (b) grid, (c) full honeycomb, (d) partial honeycomb, (e) wave, and (f) triangle

Table 1 Specimen dimensions type 1B, ISO 527-2: 2012 standard [14]

\begin{tabular}{lcc}
\hline Main dimensions & Value $(\mathrm{mm})$ \\
\hline Overall length & 150 \\
Gauge length & Width $(b)$ & 50 \\
& Thickness $(h)$ & 10 \\
Cross section & 4 \\
Width of the gripping part & 20 \\
\hline
\end{tabular}

to measurement. Humidity has a significant influence on the measured values [15], so it was important that all the test pieces had the same moisture content to match the results.

\subsection{Test pieces printing}

The FDM 3D printer type Bq Witbox 2 has been employed to print the test pieces utilizing PLA and HT-PLA filaments. HT-PLA means (High Tensile/High Temperature PLA, i.e. high strength and heat-resistant PLA) [16]. An identical number of (three) specimens of each material were printed with 12 different settings, i.e. for each individual print setting, three similar samples have been investigated, the total is 72 pieces.

Fig. 5 shows the printed specimens for mechanical measurement. HT-PLA test pieces were heat-treated, as recommended by the manufacturer. In a pre-heating oven at $80-100{ }^{\circ} \mathrm{C}$, the specimens were heat-treated for $20 \mathrm{~min}$ utes and left to cool down slowly. As a result, the polymer structure is arranged in a crystal lattice.

Simplify3D slicing software was used for setting the different parameters of the $3 \mathrm{D}$ printing process. The three main examined parameters were; the raster direction angles, print orientation and fill factor. Six raster direction angles have been tested, which are $0^{\circ}, 45^{\circ}$, $90^{\circ}$, crossed $0^{\circ} / 45^{\circ}$, crossed $+45^{\circ} /-45^{\circ}$, and crossed $0^{\circ} / 90^{\circ}$. Three print orientations were evaluated, which can be $X$, $Y$, or $Z$. Additionally, the evaluated fill factor are $50 \% X$, $50 \% Y$, and $50 \% Z$. When printing various raster directions, the print orientation is $X$. While for the varying of print orientation, the raster direction set as $+45^{\circ} /-45^{\circ}$. For specimens printed with a $50 \%$ fill factor, the inner fill

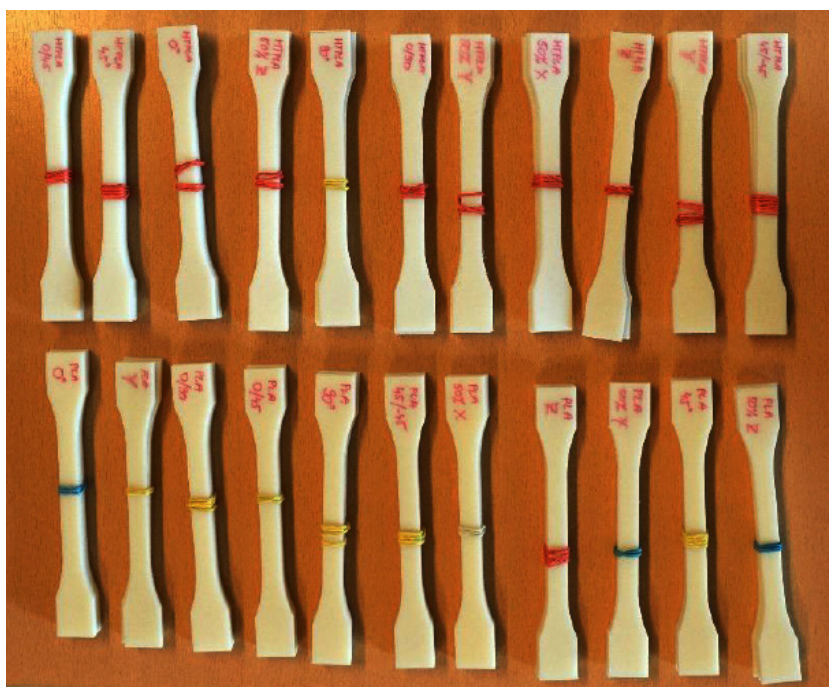

Fig. 5 Specimens (top line: HT-PLA, bottom line: PLA) 
pattern was chosen as a honeycomb structure. The thickness of layers in all specimens is $0.2 \mathrm{~mm}$. Table 2 summarizes the examined parameters.

\section{Results and discussion}

\subsection{Print precision}

Tables 3 and 4 show the print accuracy of the specimens' cross section dimensions, the width $(b)$ and the

\begin{tabular}{lrcc}
\multicolumn{4}{c}{ Table 2 Summary of the experimental settings plan } \\
\hline Parameter & $\begin{array}{c}\text { Variables } \\
\text { Raster direction }\end{array}$ & Orientation & Fill factor \\
\hline Raster angle & $\begin{array}{r}* 0^{\circ}, 45^{\circ}, 90^{\circ}, \\
\mathrm{crossed}\left(0 / 45^{\circ},\right. \\
\left.+45 /-45^{\circ}, 0 / 90^{\circ}\right)\end{array}$ & $\begin{array}{c}\text { Crossed } \\
+45^{\circ} /-45^{\circ}\end{array}$ & $\begin{array}{c}\text { Crossed } \\
+45^{\circ} /-45^{\circ}\end{array}$ \\
Orientation & $X$ & $* X, Y, Z$ & $* X, Y, Z$ \\
Filling rate & $100 \%$ & $100 \%$ & $* 50 \%$ \\
Fill pattern & Straight & Straight & Honeycomb \\
Thickness & $0.2 \mathrm{~mm}$ & $0.2 \mathrm{~mm}$ & $0.2 \mathrm{~mm}$ \\
\hline
\end{tabular}

* The cells, marked with an asterisk, represent the variables of each examined set.

\begin{tabular}{lcccc}
\multicolumn{5}{c}{ Table 3 Print accuracy of PLA specimen dimensions } \\
\hline Setting & $\begin{array}{c}\text { Width } \\
(\mathrm{mm})\end{array}$ & $\begin{array}{c}S \\
(\mathrm{~mm})\end{array}$ & $\begin{array}{c}\text { Thickness } \\
(\mathrm{mm})\end{array}$ & $\begin{array}{c}S \\
(\mathrm{~mm})\end{array}$ \\
\hline $0^{\circ}$ & 10.10 & 0.05 & 4.00 & 0.00 \\
$45^{\circ}$ & 10.07 & 0.03 & 4.20 & 0.00 \\
$90^{\circ}$ & 10.07 & 0.06 & 4.22 & 0.03 \\
$0^{\circ} / 45^{\circ}$ & 10.18 & 0.03 & 4.12 & 0.03 \\
$45^{\circ} / 45^{\circ}$ & 10.08 & 0.03 & 4.18 & 0.03 \\
$0^{\circ} / 90^{\circ}$ & 10.15 & 0.05 & 4.17 & 0.03 \\
$X$ & 10.08 & 0.03 & 4.18 & 0.03 \\
$Y$ & 10.22 & 0.03 & 4.00 & 0.00 \\
$Z$ & 9.95 & 0.00 & 4.07 & 0.03 \\
$50 \% X$ & 10.05 & 0.03 & 4.05 & 0.00 \\
$50 \% Y$ & 10.20 & 0.00 & 4.03 & 0.03 \\
$50 \% Z$ & 10.10 & 0.05 & 4.12 & 0.03 \\
\hline
\end{tabular}

\begin{tabular}{|c|c|c|c|c|}
\hline Setting & $\begin{array}{l}\text { Width } \\
(\mathrm{mm})\end{array}$ & $\begin{array}{c}S \\
(\mathrm{~mm})\end{array}$ & $\begin{array}{c}\text { Thickness } \\
(\mathrm{mm})\end{array}$ & $\begin{array}{c}S \\
(\mathrm{~mm})\end{array}$ \\
\hline $0^{\circ}$ & 10.28 & 0.03 & 4.10 & 0.05 \\
\hline $45^{\circ}$ & 10.10 & 0.00 & 4.12 & 0.03 \\
\hline $90^{\circ}$ & 10.05 & 0.05 & 4.18 & 0.08 \\
\hline $0^{\circ} / 45^{\circ}$ & 10.20 & 0.00 & 4.17 & 0.00 \\
\hline $45^{\circ}-45^{\circ}$ & 10.13 & 0.06 & 4.10 & 0.00 \\
\hline $0^{\circ} / 90^{\circ}$ & 10.23 & 0.03 & 4.13 & 0.03 \\
\hline$X$ & 10.13 & 0.06 & 4.10 & 0.00 \\
\hline$Y$ & 10.23 & 0.03 & 4.13 & 0.03 \\
\hline$Z$ & 10.23 & 0.03 & 4.25 & 0.00 \\
\hline $50 \% X$ & 10.07 & 0.06 & 4.12 & 0.03 \\
\hline $50 \% Y$ & 10.17 & 0.03 & 4.03 & 0.03 \\
\hline $50 \% Z$ & 10.08 & 0.03 & 4.15 & 0.00 \\
\hline
\end{tabular}

thickness $(h)$ with each print setting. The apparent values are the average of measured dimensions. The standard deviation $(S)$ has been calculated as well.

The biggest difference in PLA width is in the case of the test specimen $Y, 0.22 \mathrm{~mm}$. The smallest, $50 \%$ fill factor for $X$ orientation and for the specimen printed in $Z$ orientation is $0.05 \mathrm{~mm}$. Thickness is the largest with a $90^{\circ}$ raster, $0.22 \mathrm{~mm}$. Whereas the typical size was measured in the $0^{\circ}$ and $Y$ orientation printed specimens.

For HT-PLA polymer, the $0^{\circ}$ raster specimen has the largest width deviation of $0.28 \mathrm{~mm}$ relative to the ideal size. The smallest is in the $90^{\circ}$ raster, $0.05 \mathrm{~mm}$. Compared to the typical thickness, the maximum deviation was measured in the $Z$ orientation of $0.25 \mathrm{~mm}$, while the minimum which its value is $0.03 \mathrm{~mm}$ observed at $50 \%$ fill factor in $Y$ orientation.

\subsection{Strength analysis of 3D printed PLA specimens}

It can be seen in Fig. 6 that most of the tensile curves of PLA specimens are those of brittle plastics, except the specimens at $45^{\circ}, 0^{\circ} / 45^{\circ}, 45^{\circ} /-45^{\circ}, 0^{\circ} / 90^{\circ}$ raster direction which appear as tough plastics with a typical yield

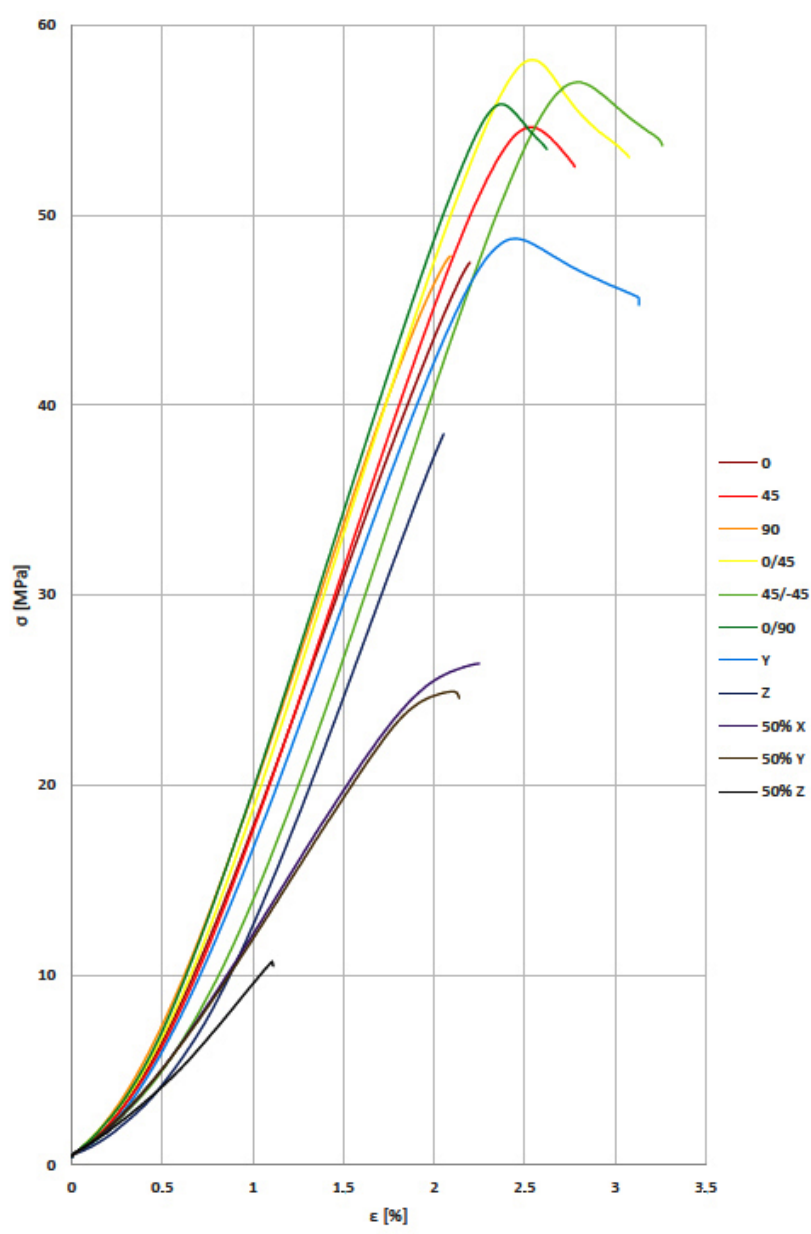

Fig. 6 Stress-strain curves of PLA specimens 
limit and not followed by a hardening phase. It can be observed that at the tensile curves of $50 \% X, 50 \% Y$, and $50 \% Z$ orientations, the linear elastic deformation and viscoelastic sections have the same slope.

Fig. 7 shows the tensile strength of PLA printed with different raster directions. The smallest value was measured at a $0^{\circ}$ raster printed specimen, averaging 48.7 $\mathrm{MPa}$ and standard deviation of $1.47 \mathrm{MPa}$. The highest at $0 \% / 45^{\circ}$, averaging $58.4 \mathrm{MPa}$ and $0.40 \mathrm{MPa}$ deviation. That means the difference between the largest and the smallest is $17 \%$. Of the non-crossed raster direction specimens $\left(0^{\circ}, 45^{\circ}\right.$, and $\left.90^{\circ}\right)$, the tensile strength of the $45^{\circ}$ specimens proved to be the highest, while $0^{\circ}$ and $90^{\circ}$ showed almost the same strength properties. This is interesting because it was expected that the perpendicular raster direction has worse properties than the parallel to the direction of the longitudinal axis. Fig. 8 presents the broken specimens, and how the specimens printed with different raster directions are torn.

Fig. 9 shows tensile strength of PLA printed with various spatial orientations and filling factor. The difference between the tensile strength of test pieces $100 \%$ filled and $50 \%$ honeycomb grid filled is noticeable. It is almost half of the $100 \%$ fill factor for $X$ and $Y$ orientations, while in the $Z$ orientation it is roughly a quarter. This indicates that the weakness of the body printed in $Z$ orientation is more significant than the other two orientations. The $X$-orientated test specimens are the highest among their sets, $100 \%$ filled is $56.5 \mathrm{MPa}$ with a deviation of $1.06 \mathrm{MPa}$, while the $50 \%$ fill factor is $26.9 \mathrm{MPa}$ and $0.11 \mathrm{MPa}$ deviation. This is followed by $Y$ orientation which its tensile strengths and deviations of $49.1 \mathrm{MPa}, 0.31 \mathrm{MPa}$ and $25 \mathrm{MPa}, 0.09 \mathrm{MPa}$ for the $100 \%$ and $50 \%$ fill factor respectively. Finally, the mechanical properties of the specimens printed in $Z$ orientation are the weakest. The $100 \%$ fill factor averaging 35.6 $\mathrm{MPa}$ with $2.51 \mathrm{MPa}$ deviation, while the $50 \%$ honeycomb grid filling is $9.5 \mathrm{MPa}$ and deviation of $0.10 \mathrm{MPa}$.

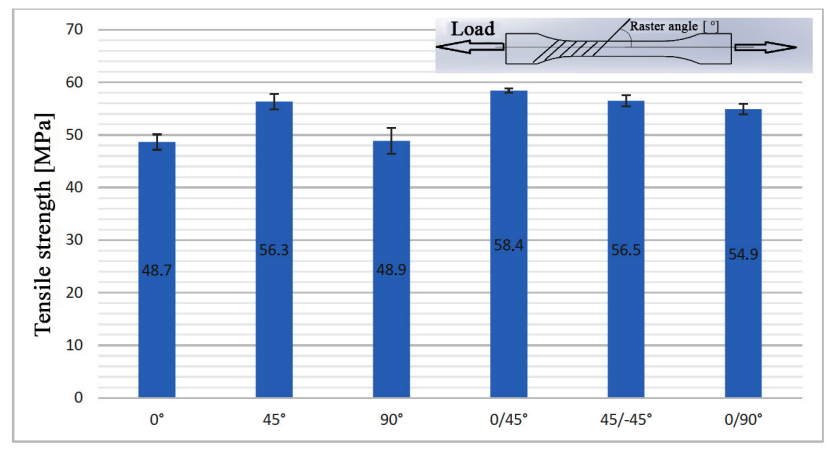

Fig. 7 Tensile strength of PLA specimens at various raster directions

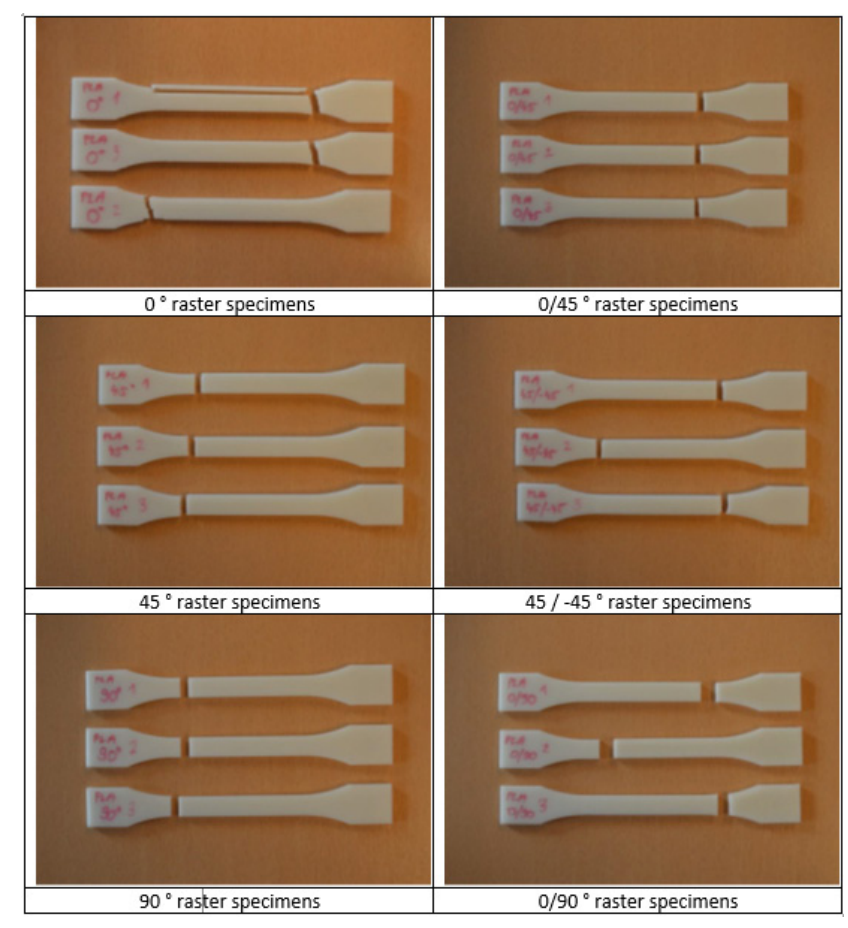

Fig. 8 Broken PLA specimens printed with different raster directions

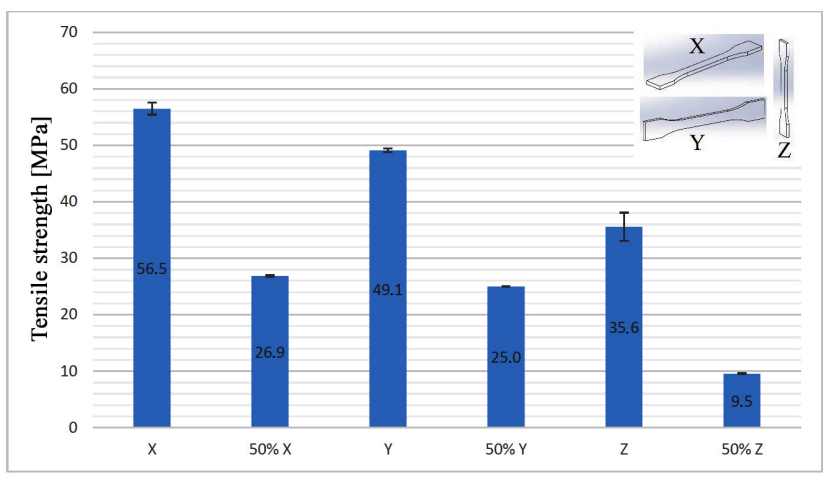

Fig. 9 Tensile strength of PLA at spatial orientations and $50 \%$ fill factor

The difference between the maximum and minimum PLA tensile strength of the investigated print orientations with $100 \%$ filled is $37 \%$, whereas $35 \%$ for the specimens with the $50 \%$ fill factor. Based on the above results, orientation should be appropriately chosen when printing a body, due to the direction of the stresses on the body will affect the mechanical properties. In the current case, the $X$ and $Y$ orientations reached the highest tensile strength because the fiber direction was parallel to the pull direction. Fig. 10 shows the broken specimens after the tensile test.

\subsection{Strength analysis of printed HT-PLA specimens}

The tensile curves of HT-PLA specimens shown in Fig. 11 are of the shape of the brittle plastics. In contrast to PLA polymer, the yield limit has entirely disappeared. It can 


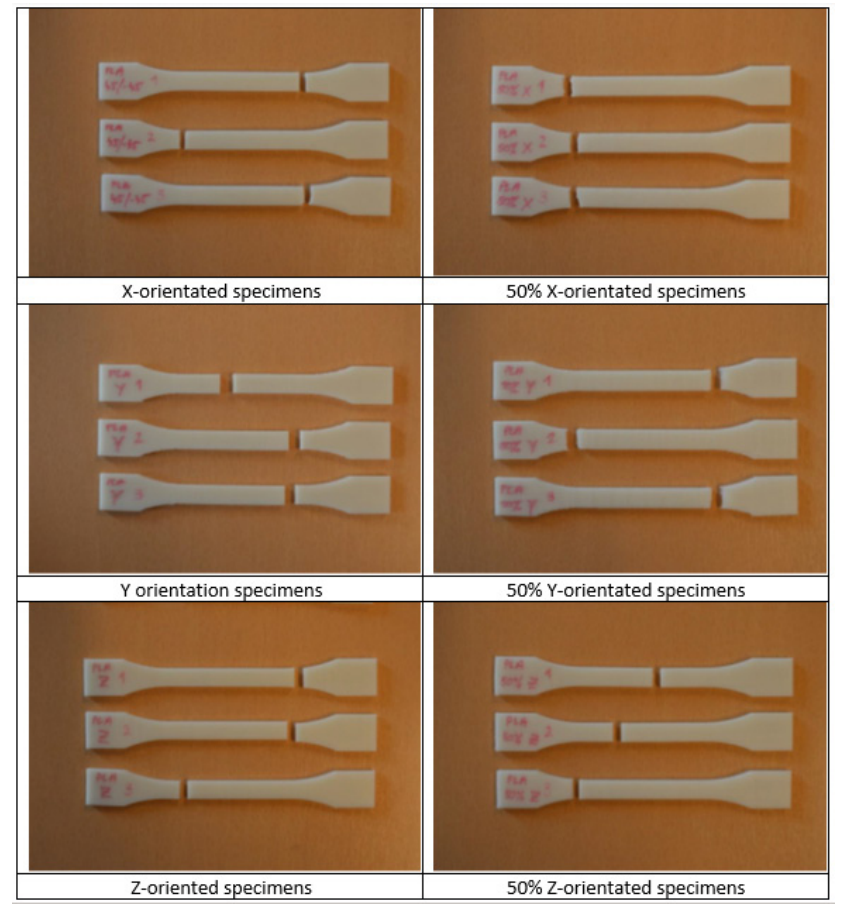

Fig. 10 Broken PLA specimens at spatial orientations and $50 \%$ filling

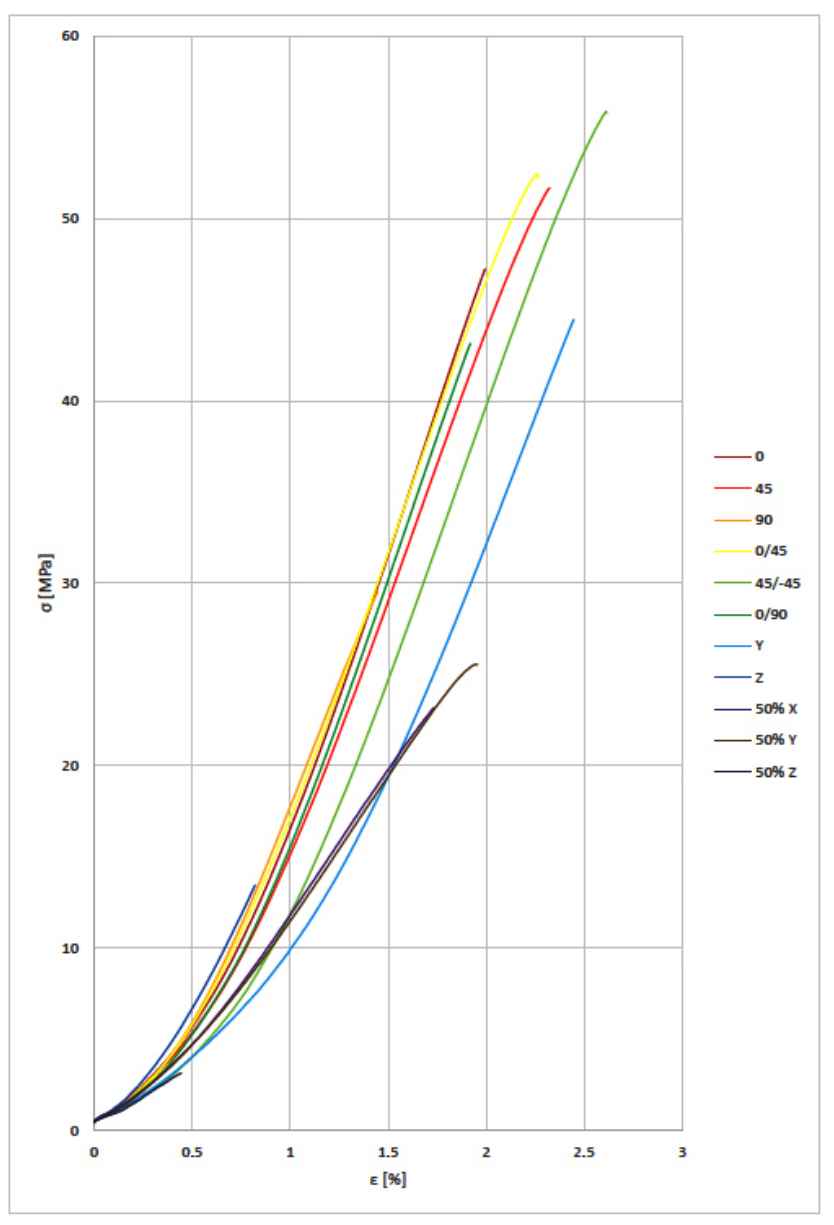

Fig. 11 Stress-strain curves of HT-PLA test specimens also be observed that the slope of the initial linear section of $50 \% X, 50 \% Y$ and $50 \% Z$ is different from other printed test specimens.

Fig. 12 shows the average tensile strength of HT-PLA printed with different raster directions. The results do not appear better mechanical properties compared to the PLA polymer. Except at $45^{\circ} /-45^{\circ}$ raster direction, the tensile strength was measured with a higher value of $59.7 \mathrm{MPa}$ and deviation of $3.36 \mathrm{MPa}$. Furthermore, the deviations are almost more significant than the PLA. For instance, its value at the $45^{\circ}$ raster direction is $9.96 \mathrm{MPa}$, which is exceptionally high. In the case of non-crossed raster direction specimens $\left(0^{\circ}, 45^{\circ}\right.$, and $\left.90^{\circ}\right)$, the highest tensile strength is $47.5 \mathrm{MPa}$ with $1.49 \mathrm{MPa}$ deviation at $0^{\circ}$. Whereas the minimum was observed at $90^{\circ}$ with a value of $33 \mathrm{MPa}$ and $4.91 \mathrm{MPa}$ deviation.

The difference between the largest and the smallest measured values of HT-PLA printed at various raster directions is $45 \%$, while PLA was only $17 \%$.

Fig. 13 exhibits the broken specimens. For specimens printed with $45^{\circ}$ and $90^{\circ}$ raster, the direction of fracture is the same as the raster direction.

Fig. 14 presents the average tensile strength values of HT-PLA specimens printed with different spatial orientations and fill factors. The tendency is the same as that of PLA, i.e. the mean value in $X$ orientation is the highest as $59.7 \mathrm{MPa}$ with a standard deviation of $3.36 \mathrm{MPa}$. This is followed by $Y$ orientation with strength and deviation values of $49.7 \mathrm{MPa}$ and $4.74 \mathrm{MPa}$ consecutively. Finally, the $Z$ orientation offered the lowest strength of 10.1 MPa and 3.04 MPa deviation. Regarding, the specimens printed with $50 \%$ fill factor and a honeycomb grid, the tensile strength for all three orientations was approximately halved. The $Y$ orientation reached the highest value by $25.5 \mathrm{MPa}$ and $0.14 \mathrm{MPa}$ deviation. This is

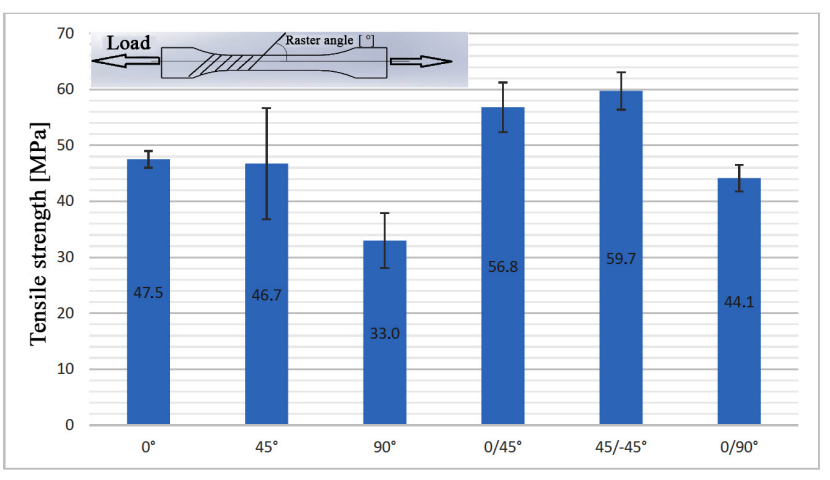

Fig. 12 Tensile Strength of HT-PLA printed at various raster directions 


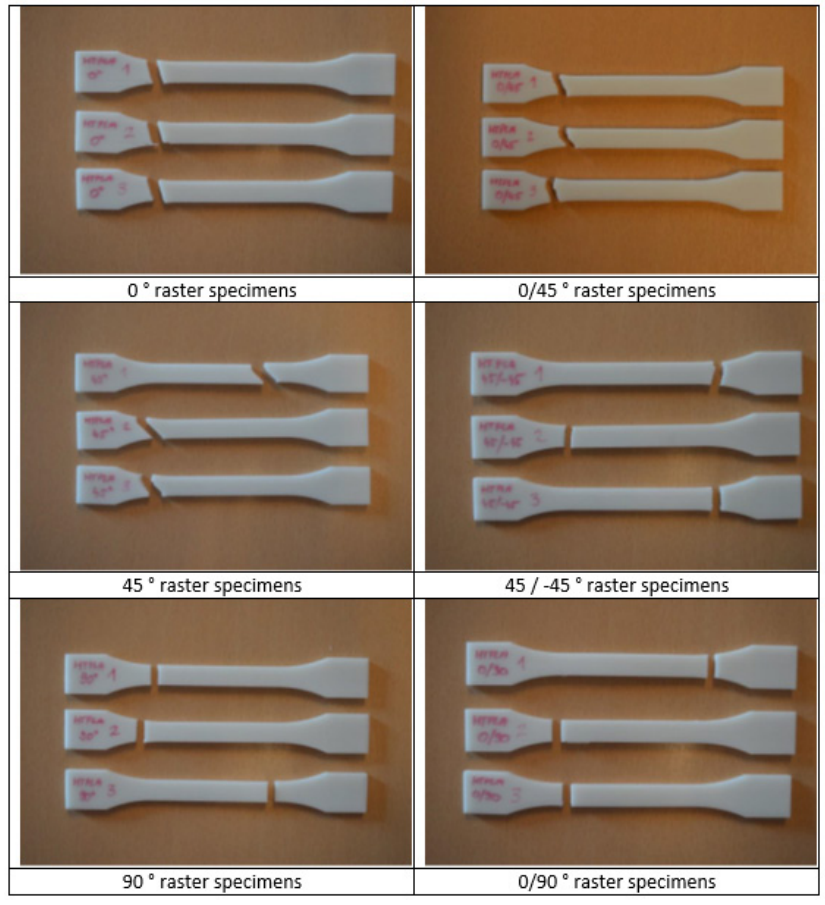

Fig. 13 Broken HT-PLA specimens at different raster directions

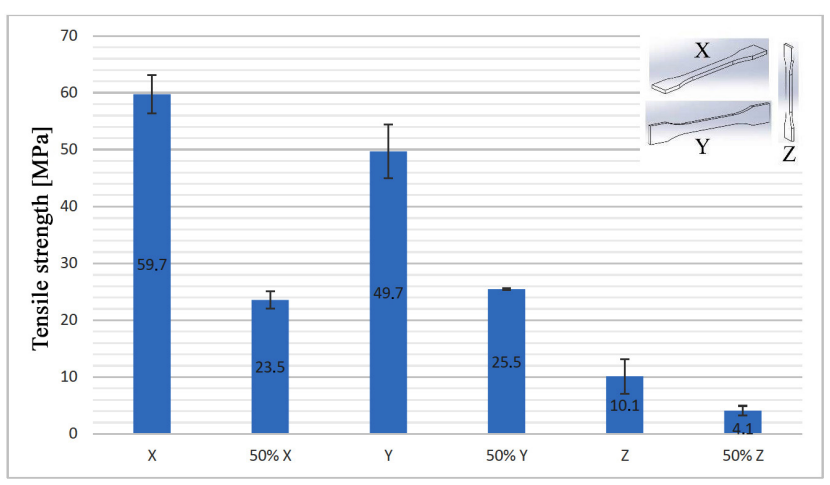

Fig. 14 Tensile Strength of HT-PLA at spatial orientations and $50 \%$ fill

followed by orientation $X$ with $23.5 \mathrm{MPa}$ and deviation of 1.53 MPa. Lastly, the lowest tensile strength was measured in the $Z$ orientation averaging 4.1 MPa with a deviation of $0.86 \mathrm{MPa}$.

For the orientations examined, both the $100 \%$ and the $50 \%$ filling specimens showed a difference between the maximum and minimum tensile strength values of $83 \%$. This emphasizes that the print orientation significantly influences the tensile strength of the printed object. The fractured specimens are shown in Fig. 15.

\subsection{Compare results}

\subsubsection{Tensile curves}

Characteristic results of tensile curves of $45^{\circ} /-45^{\circ}$ raster direction specimens are displayed in Fig. 16, to compare the differences between the investigated materials.

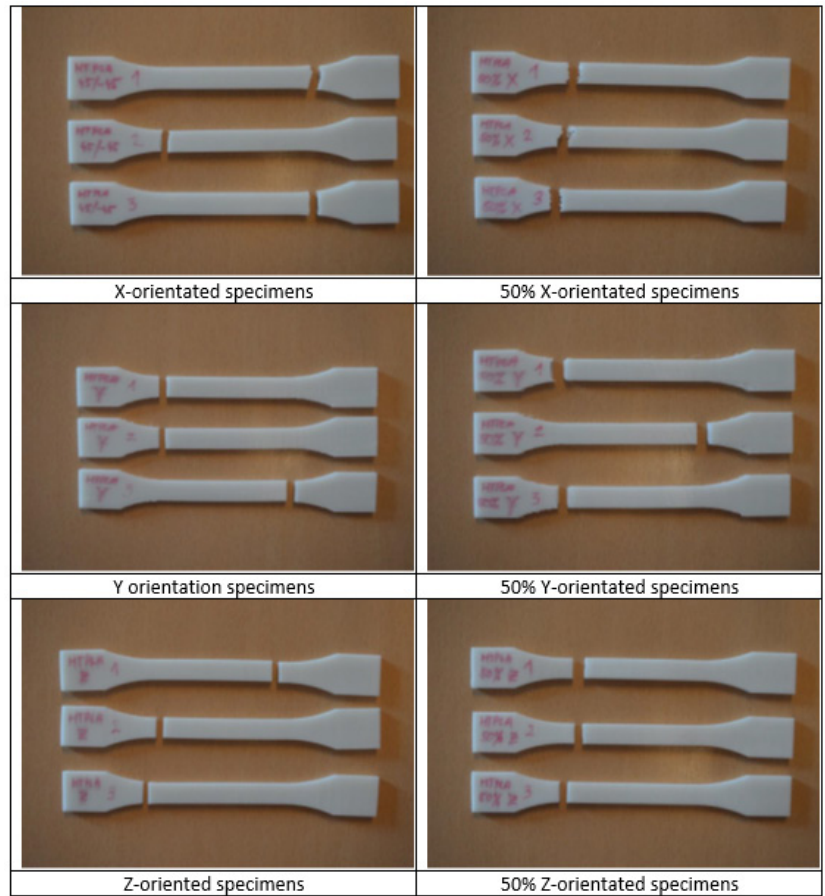

Fig. 15 Broken HT-PLA specimens at spatial orientations and infill $50 \%$

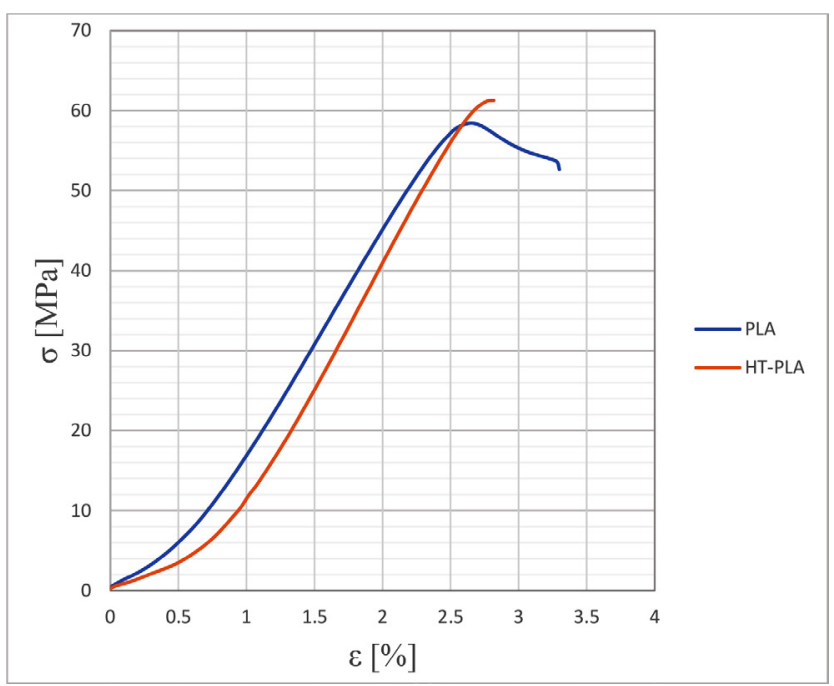

Fig. 16 Stress-strain curves of specimens printed in raster $45 \%-45^{\circ}$

HT-PLA is a brittle plastic with no yield limit. The PLA is also a brittle plastic, but it has a yield limit at this print setting (orientation and raster direction). None of the materials has a hardening section. The elongation at break is the highest in PLA with a value of nearly $3.4 \%$, while in the HT-PLA is $2.8 \%$.

\subsubsection{Raster directions}

Fig. 17 shows the average tensile strength of the examined materials at different raster directions. As mentioned earlier, the HT-PLA polymer did not attain the highest tensile strength except in the $45^{\circ} /-45^{\circ}$ raster direction specimen. 


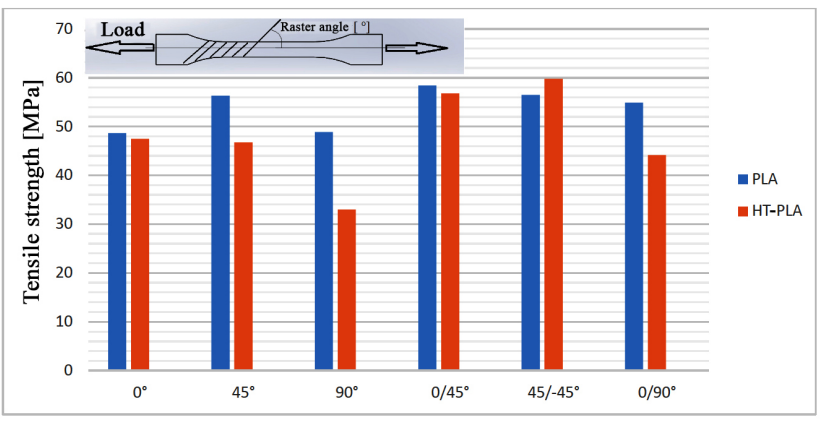

Fig. 17 Comparative chart of tensile strengths of raster direction specimens

The PLA elongation at break is on an average 10-20\% higher, as seen in Fig. 18.

\subsubsection{Spatial orientations and fill factor}

Fig. 19 presents the average tensile strength of the two tested materials at diverse spatial orientations. The $X$-orientation specimens achieved the highest tensile strength, including HT-PLA, with an average value of nearly $60 \mathrm{MPa}$. This is followed by $Y$ orientation, where both materials are about $50 \mathrm{MPa}$. Finally, the minimum

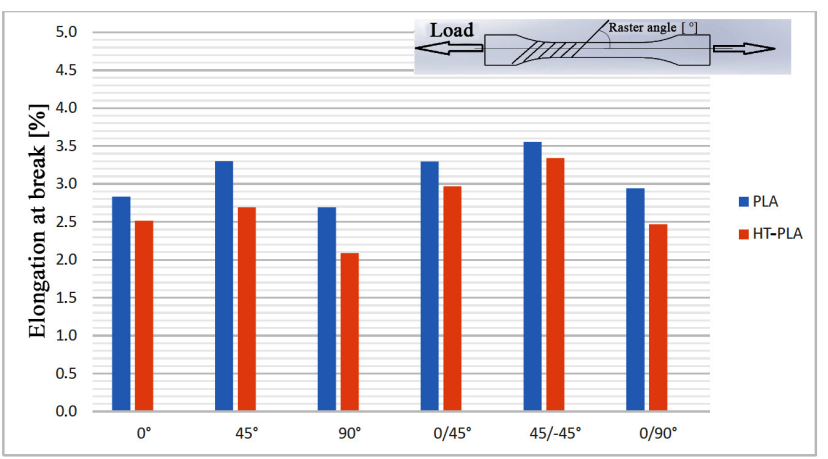

Fig. 18 Comparative chart of elongation at break of raster direction specimens

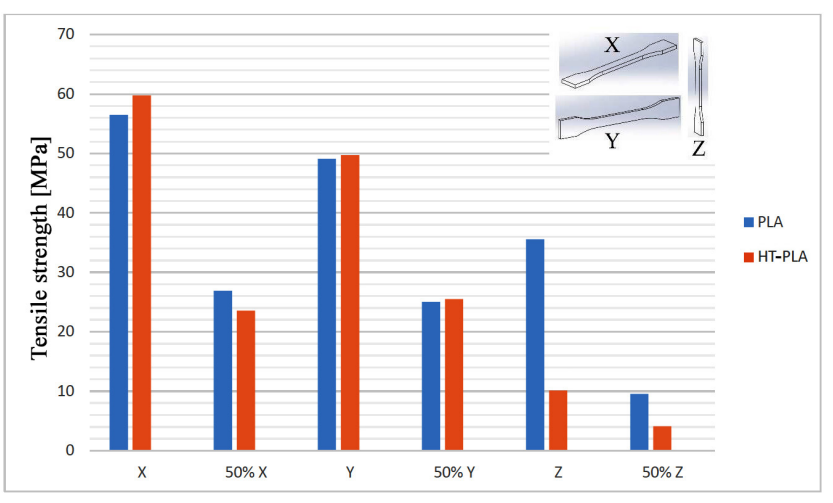

Fig. 19 Comparative chart of tensile strengths at various spatial orientations tensile strengths were measured at the $Z$ orientation. In the case of PLA, the tensile strength of the $Z$ orientated specimen is significantly higher than the other material. The $50 \%$ filling test specimens have a tensile strength of almost half that of $100 \%$ except for the $Z$ orientation, where the PLA polymer is larger than the mentioned difference as compared to the $100 \%$ fill. The average values of elongation at break are demonstrated in Fig. 20. The PLA offers the highest values.

\section{Conclusion}

In this paper, the mechanical properties of the FDM 3D printing technology have been examined. Two different materials, PLA and HT-PLA plastics were investigated. More than 70 tensile test specimens were printed with different settings and measured their values of tensile strength and elongation at break. Based on the results, the following points can be concluded:

- Orientations and raster directions have a significant effect on the tensile strength and elongation values of the printed bodies.

- The fill factor of $50 \%$ revealed weakness regarding the tensile strength, since the strength values are almost halved in opposite with $100 \%$. Whereas concerning elongation, both filling factors $(50 \%$ and $100 \%$ ) are approaching to be the same.

- Among the tested materials, the highest tensile strength was measured at HT-PLA, while the PLA demonstrated the most substantial elongation. Both cases at $45^{\circ} /-45^{\circ}$ raster direction, $X$ orientation and $100 \%$ fill factor.

- The results show that FDM 3D printing technology has really anisotropic properties, it can be seen in the tests carried out.

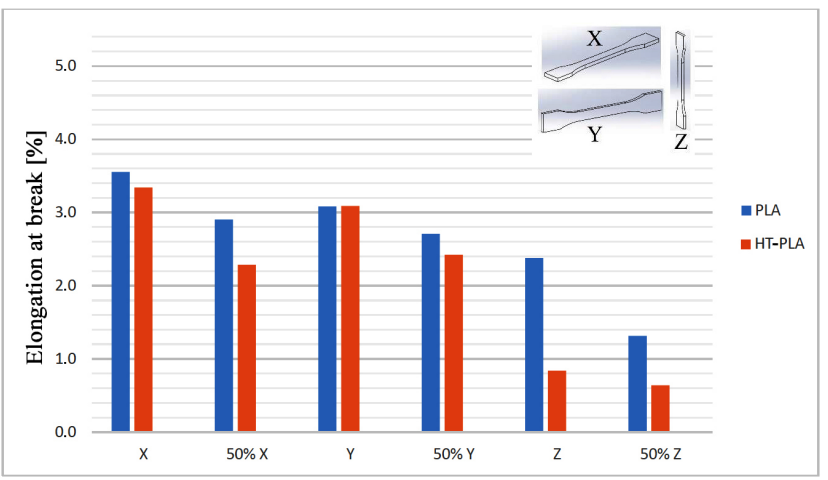

Fig. 20 Comparative chart of elongation at break at various spatial orientations 
Further research would explore the effect of altering other parameters, or the mechanical properties of bodies printed with other technologies.

\section{References}

[1] Berman, B. "3-D printing: The new industrial revolution", Business Horizons, 55(2), pp. 155-162, 2012.

https://doi.org/10.1016/j.bushor.2011.11.003

[2] Campbell, T., Williams, C., Ivanova, O., Garrett, B. "Could 3D Printing Change to World? Technologies, Potential, and Implications of Additive Manufacturing", Atlantic Council, Washington, DC, USA, Strategic Foresight Report, 2011. [online] Available at: https://www.atlanticcouncil.org/in-depth-researchreports/report/could-3d-printing-change-the-world/ [Accessed: 29 December 2018]

[3] Turner, B. N., Strong, R., Gold, S. A. "A review of melt extrusion additive manufacturing processes: I. Process design and modeling", Rapid Prototyping Journal, 20(3), pp. 192-204, 2014.

https://doi.org/10.1108/RPJ-01-2013-0012

[4] Carneiro, O. S., Silva, A. F., Gomes, R. "Fused deposition modeling with polypropylene", Materials \& Design, 83, pp. 768-776, 2015. https://doi.org/10.1016/j.matdes.2015.06.053

[5] Ahn, S.-H., Montero, M., Odell, D., Roundy, S., Wright, P. K. "Anisotropic material properties of fused deposition modeling ABS", Rapid Prototyping Journal, 8(4), pp. 248-257, 2002. https://doi.org/10.1108/13552540210441166

[6] Wang, L., Gramlich, W. M., Gardner, D. J. "Improving the impact strength of Poly(lactic acid) (PLA) in fused layer modeling (FLM)", Polymer, 114, pp. 242-248, 2017. https://doi.org/10.1016/j.polymer.2017.03.011

[7] Tran, P., Ngo, T. D., Ghazlan, A., Hui, D. "Bimaterial 3D printing and numerical analysis of bio-inspired composite structures under in-plane and transverse loadings", Composites Part B: Engineering, 108, pp. 210-223, 2017.

https://doi.org/10.1016/j.compositesb.2016.09.083

[8] Letcher, T., Waytashek, M. "Material Property Testing of 3D-Printed Specimen in PLA on an Entry-Level 3D Printer", In: ASME 2014 International Mechanical Engineering Congress and Exposition, Montreal, Quebec, Canada, 2014, Article Number: V02AT02A014. https://oi.org/10.1115/IMECE2014-39379

[9] Tymrak, B. M., Kreiger, M., Pearce, J. M. "Mechanical properties of components fabricated with open-source 3-D printers under realistic environmental conditions", Materials \& Design, 58, pp. 242-246, 2014.

https://doi.org/10.1016/j.matdes.2014.02.038

\section{Acknowledgement}

This work was supported by the Stipendium Hungaricum Programme and by the Mechanical Engineering Doctoral School, Szent István University, Gödöllö, Hungary.

[10] Galeta, T., Raos, P., Stojšić, J., Pakši, I. "Influence of Structure on Mechanical Properties of 3D Printed Objects", Procedia Engineering, 149, pp. 100-104, 2016. https://doi.org/10.1016/j.proeng.2016.06.644

[11] Lanzotti, A., Grasso, M., Staiano, G., Martorelli, M. "The impact of process parameters on mechanical properties of parts fabricated in PLA with an open-source 3-D printer", Rapid Prototyping Journal, 21(5), pp. 604-617, 2015. https://doi.org/10.1108/RPJ-09-2014-0135

[12] Ferreira, R. T. L., Amatte, I. C., Dutra, T. A., Bürger, D. "Experimental characterization and micrography of 3D printed PLA and PLA reinforced with short carbon fibers", Composites Part B: Engineering, 124, pp. 88-100, 2017. https://doi.org/10.1016/j.compositesb.2017.05.013

[13] Torrado, A. R., Roberson, D. A. "Failure Analysis and Anisotropy Evaluation of 3D-Printed Tensile Test Specimens of Different Geometries and Print Raster Patterns", Journal of Failure Analysis and Prevention, 16(1), pp. 154-164, 2016. https://oi.org/10.1007/s11668-016-0067-4

[14] International Organization for Standardization "ISO 527-2:2012 Plastics - Determination of tensile properties - Part 2: Test conditions for moulding and extrusion plastics", International Organization for Standardization, Geneva, Switzerland, 2012. [online] Available at: https://www.iso.org/standard/56046.html [Accessed: 29 December 2018]

[15] Müller, C. M. O., Laurindo, J. B., Yamashita, F. "Effect of cellulose fibers on the crystallinity and mechanical properties of starchbased films at different relative humidity values", Carbohydrate Polymers, 77(2), pp. 293-299, 2009. https://doi.org/10.1016/j.carbpol.2008.12.030

[16] 3Dee Store Budapest "HT-PLA - High Temperature PLA", [online] Available at: https://3dee.hu/termek/ht-pla-001/ [Accessed: 29 December 2018] 